\title{
Anabases
}

ANABASES Traditions et réceptions de l'Antiquité

$7 \mid 2008$

Varia

\section{Hédi DRIDI, Carthage et le monde punique (Guide Belles Lettres des Civilisations)}

\section{Véronique Krings}

\section{OpenEdition}

\section{Journals}

Édition électronique

URL : http://journals.openedition.org/anabases/2602

DOI : 10.4000/anabases.2602

ISSN : 2256-9421

\section{Éditeur}

E.R.A.S.M.E.

\section{Édition imprimée}

Date de publication : 1 mars 2008

Pagination : 316-317

ISSN : 1774-4296

\section{Référence électronique}

Véronique Krings, "Hédi DRIDI, Carthage et le monde punique (Guide Belles Lettres des Civilisations)», Anabases [En ligne], 7 | 2008, mis en ligne le 01 décembre 2011, consulté le 22 septembre 2020. URL http://journals.openedition.org/anabases/2602 ; DOI : https://doi.org/10.4000/anabases.2602

Ce document a été généré automatiquement le 22 septembre 2020.

(c) Anabases 


\title{
Hédi DRIDI, Carthage et le monde punique (Guide Belles Lettres des Civilisations)
}

\author{
Véronique Krings
}

\section{RÉFÉRENCE}

Hédi DRIDI, Carthage et le monde punique (Guide Belles Lettres des Civilisations), Paris, Les Belles Lettres, 2006, $288 \mathrm{p}$.

15 euros / ISBN 2-251-41033-3.

1 Le présent ouvrage est le vingt et unième à paraître dans la collection "Guide Belles Lettres des Civilisations" où l'on trouve des volumes consacrés, pour ce qui est de l'Antiquité, à Rome, à la Grèce classique, à la Mésopotamie, aux Étrusques, aux Gaulois et à la Perse antique. De façon générale, cette collection s'efforce par divers moyens de rendre accessible une civilisation, à travers d'une part des chapitres clairement délimités et découpés qui couvrent les facettes essentielles de celle-ci, d'autre part, des annexes - ici constituées de repères biographiques, d'un lexique punique, d'une orientation bibliographique, de deux index (général et noms de personnes)-, l'ensemble étant accompagné de tableaux, de cartes et plans, de figures et d'encadrés thématiques. L'utilisation du guide peut donc se faire de deux façons : soit il se lit de manière continue comme un livre traditionnel, soit on l'utilise comme un instrument de travail, puisque l'accès à l'information est facilité par son organisation très pratique. Cette approche est particulièrement utile dans le cas présent, car aujourd'hui encore par ses descriptions hautement colorées dans Salammbô, Flaubert a largement contribué au mythe de Carthage -, la cité punique reste méconnue en dehors du monde des spécialistes et souvent réduite à un certain nombre de clichés. Sa représentation dans les romans, la bande dessinée ou les arts du spectacle amène ainsi souvent à s'interroger sur la «réalité » de tel ou tel trait de civilisation - les sacrifices humains 
évidemment, mais aussi ses dieux et sa mythologie, le cadre urbanistique de Carthage, la vie quotidienne - et sur ses grands personnages - Élissa/Didon sa légendaire fondatrice, mais aussi les généraux carthaginois tels Hamilcar Barca ou son fils Hannibal. Pour répondre à ces questions, la bibliographie en langue française est déjà dotée d'un Carthage de S. Lancel (Fayard, 1992) ou encore de La légende de Carthage d'A. Beschaouch (Gallimard, 1993), qui fait une place à la Carthage punique. Ces ouvrages cf. pour d'autres titres la bibliographie rassemblée par l'A. (p. 265-272) - seront heureusement complétés par ce guide qui d'une part actualise l'information des précédents, et d'autre part propose une approche un peu différente. En effet, l'étude du monde punique pose la question des modalités, des difficultés et des limites de notre connaissance de cette civilisation et de son histoire. En l'absence d'une littérature punique qui soit parvenue en l'état jusqu'à nous, les sources classiques (les auteurs grecs et latins) et la Bible y ont longtemps constitué le premier accès (cela vaut pour Flaubert aussi), avec à l'arrivée une image déformée par les préjugés des auteurs anciens et des chercheurs modernes dans leur approche d'une civilisation non classique. Cet état de fait, qui a suscité débats et polémiques (depuis Flaubert!) constituerait aujourd'hui plutôt un stimulus dans l'étude du monde punique, en faveur à la fois d'une approche attentive de chacune des catégories de sources disponibles (outre les auteurs classiques et la Bible, les sources des autres civilisations en contact avec le monde punique, la documentation issue directement de celui-ci : épigraphie, archéologie et histoire de l'art, iconographie, numismatique), mais aussi de croisements entre elles, une approche historiographique pouvant être intégrée. Le présent ouvrage est un fruit de cette vision et d'une pratique « libérée » de la recherche sur le monde punique, pensée à l'attention d'un public de non-spécialistes. Il faut en saluer la réussite ainsi que le bel effort de ce jeune chercheur pour exposer les tenants et aboutissants de chaque dossier, y compris des plus sensibles, par exemple celui de la nature de la puissance de Carthage en Méditerranée (chapitre I sur l'histoire ; p. 83-95 sur l'espace carthaginois) ou celui du «moloch» (p. 189-194). Le support documentaire constitué de dessins au trait est bien adapté, même si on regrette que les pièces présentées ne soient pas systématiquement accompagnées de la mention d'une provenance bibliographique clairement indiquée. Au total, un guide qui devrait répondre aux interrogations de ceux qui sont curieux de choses puniques.

\section{AUTEURS}

\section{VÉRONIQUE KRINGS}

Université de Toulouse II-Le Mirail

vkrings@orange.fr 